\section{Diablo Canyon safe}

SIR - In the news article "Disaster by many small cuts" (Nature 306, 631; 1983), the following statement was made about the Pacific Gas and Electric Company's nuclear power plant at Diablo Canyon. "In California the two reactors at Diablo Canyon have only just received permission to load fuel after a year's delay caused by the last-minute discovery that the reactors, built above the San Andreas fault, would not be able to meet NRC requirements for withstanding earth tremors."

In fact, however, the Diablo Canyon power plant is located $60 \mathrm{~km}$ from the San Andreas fault and its safety in the event of a magnitude $8+$ earthquake on this fault has never been questioned.

On the nuclear power stage, there are three principal actors: the power company that wishes to construct the plant, the Nuclear Regulatory Commission that acts as referee and the organized opposition that does not want a power plant built at that location. The statements of these actors are widely reported by newspapers, especially those issued by the opposition. Unfortunately, the views of the engineers who design nuclear power plants and the views of the informed engineering community are neither reported nor sought by the news media. Consequently, much misinformation has been implanted in the public consciousness.

G.W. HOUSNER

Division of Engineering

and Applied Science,

California Institute of Technology,

Pasadena, California 91125, USA

\section{Nuclear Phoenix}

SIR - Contrary to the report of Stephen Budiansky (Nature 19 January p.201), the AIM-54 Phoenix is not new but has been manufactured since 1973. It is deployed by the US Navy on the F-14 Tomcat (the US Navy's carrier-borne long-range interceptor), and has been since the aircraft was first delivered in September 1973.

The Phoenix is very well known because of the large number of records it holds, so the fact that the report is approximately ten years out of date is worrying. Is this due to a singular although very serious mistake or does it indicate sloppiness in the preparation of the original manuscript? I hope it is the former because the general public is appallingly informed about the nature and roles of nuclear weapons and there is a real need for properly informed debate in the general population rather than the rabble-rousing that seems to be the present case

Max-Planck-Institut für

Molekulare Genetik,

Ihnestrasse 63-73,

1000 Berlin 33 (Dahlem), FRG

- Stephen Budiansky writes: What is new is the development of a nuclear warhead for this missile.

\section{In the abstract}

SIR - A correspondent recently complained about the citing of abstracts of conference presentations as literature references, primarily on the basis that they are not properly refereed. True, but the problem does not stop there. For instance, in many cases, the abstracts bear little resemblance to the paper eventually presented at the conference. In clinical papers in particular, for instance, the number of patients involved in a study as reported in the abstract may be entirely different from the number reported at the conference.

A greater problem is that many abstracts that appear in the proceedings of a meeting may actually represent papers that were never presented. This is especially true of poster presentations. At a recent conference on food technology, I found that only about 40 per cent of the posters listed in the abstracts were actually presented. Papers from Eastern Europe frequently encounter this fate because scientists for whatever reason may find it difficult to follow up their preparation of an abstract by attending the conference.

Worst of all, a paper that appears on the programme and in abstract form is sometimes withdrawn at the last moment. This happened recently at a leukaemia conference where, on the basis of the abstract, I waited for two days to hear what seemed to be one of the more interesting papers at the conference. The paper was never presented.

These criticisms apply less to small abstracts with little hard information than they do to more extensive abstracts, sometimes of full paper length. Although the latter abstracts may be very detailed, they mean very little if the paper is not presented, or if the presenter strays widely from the original script.

Abstracts may be a good guide to what is going on at a conference, but it is laughable to consider them as anything more than a remote approximation of scientific reality. 118 Ballinclea Heights, JOHN F. HENAHAN Killiney, Co. Dublin, Ireland

\section{Biophysics}

SIR - The leading article on biology as part of physics encourages me to make a general remark on holistic versus reductionist approaches in physics. Since the number of microstates increases exponentially with the number of particles, $N$, say $10^{N}$, even a super computer could, in the life time of the Universe, solve only for $N \approx 20$ unless systematic ways of finding them exist. (Compare my article on the connection of macro and micro physics, Riv. nuovo Cimento 3, 490; 1973.) Macroscopic equations, such as the Navier-Stokes equations, can, however, be derived from macro-physics without actually solving the $N$-body problem. This requires the definition of appropriate macro-concepts, such as current density, in terms of microconcepts.

When one is far from equilibrium, as in biology, a basic problem arises - namely to find the relevant macro-concepts. Structure alone is insufficient as active systems are highly excited, and hence new macro properties arise which cannot be found by systematic investigation of the $N$-body problem. From this viewpoint, the holistic and reductionist approaches supplement rather than contradict each other.

H. FrOHLICH

Department of Physics,

University of Liverpool,

Oliver Lodge Laboratory,

Liverpool L69 3BX, UK

\section{Creative paradigm}

SIR - The article on creationism in Texas (Nature 306, 528; 1983) points to what may be a more general problem in basic education. Compared with the difficult choices on complex issues that students will have to make when they are adults, the question of human origins is benign. So instead of simply absorbing "facts" in the classroom, should not students be learning how to evaluate information derived from different sources, taking into account the reliability of the source, the accuracy of the information and the consequences of their misinterpretation of the material?

This skill must be taught and encouraged; it requires a good working knowledge of language, particularly the ability to read a passage accurately and critically. Let creationism and evolution be discussed if that is what teachers, students and parents desire, but present the issues in such a way that students learn the difficulties inherent in evaluating historical material. For example, originally the Bible was not written in English or any other contemporary language in common use, and so we must question whether the authors intended to say exactly what has reached us after centuries of translation and revision.

Why not use this controversial issue as a way of training students in the proper evaluation of facts and ideas? Any idea worth being taught and passed on to the next generation ought to be able to stand up to comparison and criticism, and unless students learn this in school, they will become adults who are ready to believe anything.

J. POTTER

Strawberry Hill,

Bar Harbor, Maine 04609, USA

\section{Lesson in objectivity}

SIR - "Just how objective is science" by N.S. Hetherington (Nature 306; 727 1983) was interesting and objective. However, I think science is objective by definition. I would have entitled the article: "Just how objective are scientists?"

Clavecimbellaan 273 ,

J. M. GOLDSCHVARTZ

2287 VK Rijswijk zh, The Netherlands 